\title{
Pain and sedation during colonoscopy - a never ending story
}

Authors

Institutions
Øyvind Holme ${ }^{1,2}$, Michael Bretthauer ${ }^{1,2,3}$

${ }^{1}$ Department of Medicine, Sørlandet Hospital, Kristiansand, Norway

${ }^{2}$ Department of Health Management and Health Economics, University of Oslo, Oslo, Norway

${ }^{3}$ Department of Transplantation Medicine and KG Jebsen Center for Coilorectakl Cancer Research, Oslo University Hospital, Oslo, Norway submitted: 24. March 2016 accepted after revision: 29. March 2016

\section{Bibliography}

Dol http://dx.doi.org/

10.1055/s-0042-106085

Endoscopy International Open

2016; 04: E538-E539

(c) Georg Thieme Verlag KG

Stuttgart · New York

E-ISSN 2196-9736

Corresponding author

Øyvind Holme, MD, PhD

Sorlandet Hospital Kristiansand,

Postbox 416

4604 Kristiansand

Norway

oyvind.holme@medisin.uio.no
In this issue of the journal, Iqbal and colleagues report on a study performed at 3 hospitals in the UK which shows that colonoscopy without sedation can be performed with an acceptable level of discomfort and with quality measures comparable to that achieved using conscious sedation [1]. Interestingly, in Iqbal's study, patients examined without sedation experienced less pain and discomfort than did patients who received sedation.

The discussion concerning unsedated colonoscopy seems to be a never-ending story. While unsedated colonoscopy is common and received well in some countries, other countries consider unsedated colonoscopy not feasible and recommend against it. In "sedation countries," there is also a trend toward more and deeper sedation [2].

Sedation may increase the burden of colonoscopy. For the community, sedation increases colonoscopy costs associated with absence from work and for the extra personnel and equipment required to administer anesthesia and monitor and supervise patient recovery. For the individual, sedation includes the need for escort and leads to activity restrictions and risk of sedation-related complications, even if such complications are rare.

Sedation can be considered for colonoscopy for 2 main reasons; 1 ) because patients are embarrassed or anxious; or 2 ) because the procedure is painful. Naturally, the 2 reasons require different drugs; for embarrassment or anxiety, benzodiazepines would be appropriate, whereas for pain, opioids are the proper agents. Another, more resource-intensive option is deep sedation using propofol, or even general anesthesia as used in some countries.

It is intriguing and confusing at the same time that colonoscopy can be performed well, with high patient satisfaction and little or no pain without sedation in some hospitals or countries, while it requires deep sedation in other places.
The question is why. We believe that the answer is multifactorial, and includes endoscopist skills, patient expectations, traditions, insertion techniques, and endoscope equipment.

New generations of colonoscopes may enable us to improve not only adenoma detection and cecum intubation rates, but also patient experience. Thinner and more flexible endoscopes may cause less stretching of the mesentery, which is one of the principal sources of pain during colonoscopy. Pediatric endoscopes have been shown to achieve higher cecum intubation rates in difficult colonoscopies than in adult colonoscopes [3]. However, due to their softness, excess looping can occur, and pain scores rated by the patients are comparable to adult colonoscopies [3, 4]. Colonoscopes with adjustable stiffness improve cecal intubation rates compared to standard colonoscopes, but their ability to reduce patient discomfort has not been uniform in randomized trials. In a meta-analysis, pain scores were not different when variable stiffness colonoscopes were compared to standard colonoscopes [5]. One could imagine that combining the 2 inventions (variable stiffness and pediatric colonoscope) would reduce discomfort, but this was disappointingly not shown in a randomized trial in routine colonoscopy [4].

A major leap ahead was achieved with the introduction of very slim colonoscopes (with an outer diameter of $9.2 \mathrm{~mm}$ to $9.6 \mathrm{~mm}$ ). Even if they are prone to cause excess looping, they induce less stretching of the mesentery and thus less painful colonoscopies. Cecum intubation abilities are not compromised with these colonoscopes as the length of the endoscopes is increased. In one randomized trial of unsedated colonoscopy with a super-slim endoscope, 200 patients were randomized to the slim-scope group, none of whom experienced severe pain, and $70 \%$ of the procedures were pain-free [6]. In another randomized trial, both maximum pain and overall pain were 
significantly reduced with the slim scope compared to a variable stiffness adult colonoscope [7]. New colonoscope prototypes, such as self-propelling scopes have not been evaluated in randomized trials that have assessed patient discomfort [8].

For many years, new technical improvements in colonoscopes have failed to significantly reduce discomfort during colonoscopy, propelling the increasing demand for deeper sedation. With the latest generation of super-slim scopes, that has changed. However, a drawback with slim endoscopes is their smaller working channel, making suction of fecal material and retrieval of polyps more difficult.

Iqbal and colleagues used air insufflation during colonoscopy. There is compelling evidence that water [9] and $\mathrm{CO}_{2}$ insufflation [10] instead of air significantly reduce patient pain and discomfort related to colonoscopy. Water or $\mathrm{CO}_{2}$ during insertion, combined with $\mathrm{CO}_{2}$ during withdrawal, are the methods of choice; air insufflation should be abandoned altogether as it represents outdated practice.

Unsedated colonoscopy requires different insertion technique. While sedated patients tolerate insertion by pushing through loops, negotiation and withdrawal and straightening out loops needs to be performed during insertion in unsedated colonoscopy. Thus, cecum intubation times in unsedated colonoscopy are often some minutes longer on average. But these minutes are well spent, as recovery time is much shorter than with sedation. In some countries, patients expect sedation during colonoscopy. That has often been used as an argument to continue with the use of sedation. It's what patients are used to. However, in a study from the United States, it has been shown that patients are happy with unsedated colonoscopy if they are introduced to it properly [11]. And they certainly gain from it because of no need for recovery, escort or restrictions on driving an automobile.

So, we may be ready to perform painless, sedation-free colonoscopies with last-generation colonoscopes. The challenge is to convey this message to our patients and, not the least, to our colleagues. As Iqbal and colleagues describe in their report, hospital factors, rather than patient factors, may be barriers to sedationfree colonoscopy.

\section{Competing interests: None}

\section{References}

1 Iqbal N, Ramcharan S, Doughan S. Colonoscopy without sedation: Patient factors alone are less likely to influence its uptake. Endoscopy International Open 2016; 4: E534-E537

2 Vaessen HH, Knape JT. Considerable Variability of Procedural Sedation and Analgesia Practices for Gastrointestinal Endoscopic Procedures in Europe. Clinical endoscopy 2016; 49: 47-55

3 Marshall JB, Perez RA, Madsen RW. Usefulness of a pediatric colonoscope for routine colonoscopy in women who have undergone hysterectomy. Gastrointest Endosc 2002; 55: 838-841

4 Shumaker DA, Zaman A, Katon RM. A randomized controlled trial in a training institution comparing a pediatric variable stiffness colonoscope, a pediatric colonoscope, and an adult colonoscope. Gastrointest Endosc 2002; 55: 172 - 179

5 Xie $Q$ Chen B, Liu L et al. Does the variable-stiffness colonoscope makes colonoscopy easier? A meta-analysis of the efficacy of the variable stiffness colonoscope compared with the standard adult colonoscope BMC gastroenterology 2012; 12: 151

6 Garborg KK, Loberg M, Matre J et al. Reduced pain during screening colonoscopy with an ultrathin colonoscope: a randomized controlled trial. Endoscopy 2012; 44: 740-746

7 Sato $K$, Ito $S$, Shigiyama $F$ et al. A prospective randomized study on the benefits of a new small-caliber colonoscope. Endoscopy 2012; 44: $746-753$

8 Groth S, Rex DK, Rosch T et al. High cecal intubation rates with a new computer-assisted colonoscope: a feasibility study. Am J Gastroenterol 2011; 106: 1075-1080

9 Hafner S, Zolk K, Radaelli $F$ et al. Water infusion versus air insufflation for colonoscopy. Cochrane Database Syst Rev 2015; 5: CD009863

10 Memon MA, Memon B, Yunus RM et al. Carbon Dioxide Versus Air Insufflation for Elective Colonoscopy: A Meta-Analysis and Systematic Review of Randomized Controlled Trials. Surg Laparosc Endosc Percutan Tech 2016; 26: $102-116$

11 Rex DK, Imperiale TF, Portish V. Patients willing to try colonoscopy without sedation: associated clinical factors and results of a randomized controlled trial. Gastrointest Endosc 1999; 49: 554-559 